\title{
TRANSPORT OF NARCOTIC ANALGESICS BY CHOROID PLEXUS AND KIDNEY TISSUE IN VITRO*
}

\author{
CARL C. Hug, JR. \\ Department of Pharmacology, The University of Michigan Medical School, \\ Ann Arbor, Mich., U.S.A.
}

(Recelved 8 August 1966; accepted 10 October 1966)

\begin{abstract}
Radioactive narcotic analgesics, including morphine, dihydromorphine, nalorphine, codeine, levorphan, dextrorphan, and $l$-methorphan were accumulated against an apparent concentration gradient in pieces of rabbit and dog choroid plexus and in slices of dog renal cortex by a metabolically dependent mechanism. The uptake of dihydromorphine by these tissues in vitro was a saturable process depressed by low temperatures, a nitrogen atmosphere, and certain metabolic inhibitors. It also was competitively inhibited by nalorphine and by any one of several organic bases which previously have been demonstrated to be actively transported by these tissues. Under certain conditions, stimulation of dihydromorphine uptake by choroid plexus was produced by organic bases. The transport in choroid plexus of one of these organic bases, hexamethonium, was competitively inhibited by dihydromorphine. Studies with levorphan and dextrophan indicated an element of stereospecificity in their accumulation by choroid plexus. Thus it is concluded that the narcotic analgesics share the same active transport mechanisms described for a variety of organic bases that are accumulated in choroid plexus and renal tissue in vitro. Suggestions are made relative to the significance of these observations for the intact animal.
\end{abstract}

A PREvious report from this laboratory ${ }^{1}$ presented evidence for active secretion of dihydromorphine by the proximal renal tubules of dogs and monkeys. The transport of this morphine-like drug had the usual characteristics described for a variety of organic bases. ${ }^{2}$ In order to more clearly define the nature of this transport, studies of the uptake of narcotic analgesics by renal tissue slices were performed. Use of the in vitro-system avoided the complex effects of the analgesics and other organic bases on organ systems other than the kidney.

Recent publications by Tochino and Schanker ${ }^{3,4}$ have reported active uptake of organic bases by the choroid plexus in vitro. These authors have postulated that the choroid plexus is a site of carrier-mediated transport for removal of organic amines from cerebrospinal fluid. ${ }^{5}$ Thus it was of interest to determine whether the narcotic analgesics are also transported by the choroid plexus. Such transport could have significant implications in terms of limiting the accumulation of these potent

* A summary of the work presented in detail here appeared in Fedn Proc. 25, 415 (1966). This investigation was supported in part by Research Grant MH-08580 from the National Institutes of Health. The investigator is a Postdoctoral Research Scholar of the American Cancer Society. 
compounds within the central nervous system and in understanding mechanisms of antagonism and potentiation of narcotic analgesic effects by a variety of drugs.

\section{METHODS}

Male and female albino rabbits (New Zealand strain) weighing approximately $2 \mathrm{~kg}$ were sacrificed by intravenous injection of air. The choroid plexus was taken from each lateral ventricle and immediately placed in ice-chilled incubation media containing no drug (plain media). Each plexus was divided into two or three pieces of equal size, and the pieces from each animal were kept separate so that tissue from each animal served as its own control.

Each piece of choroid plexus $(0 \cdot 8-3 \mathrm{mg})$ was placed in $3 \mathrm{ml}$ of Krebs-Ringer phosphate ${ }^{3,4}$ or bicarbonate-buffered fluid ${ }^{6}$ containing a radioactively labeled narcotic analgesic with or without a potential inhibitor. When compounds were added to the medium as sodium salts, the concentration of sodium chloride was reduced accordingly in order to maintain a constant concentration of sodium ion in the final medium. A carbon dioxide-oxygen mixture (5:95) was bubbled through the media when it contained bicarbonate, in order to adjust the final medium to $\mathrm{pH} 7 \cdot 4$. A rapid flow of the same gas mixture was used to provide the atmosphere for incubation in a Dubnoff metabolic shaker. When phosphate-buffered media $(\mathrm{pH} 7.4)$ were used, a rapid flow of $100 \%$ oxygen or $100 \%$ nitrogen was substituted for the carbon dioxide-oxygen mixture. After incubation, the tissue was removed from the medium, blotted on filter paper, wrapped in aluminum foil, and frozen until it was to be weighed and analyzed. Aliquots of the medium were taken immediately for analysis.

A description of the preparation, incubation, and analysis of renal slices from mongrel dogs has been published. ${ }^{1}$ The choroid plexus was also taken from the lateral ventricles of mongrel dogs anesthetized with ether, and the tissue was handled in the same way as described above for rabbit choroid plexus.

The method for analysis of radioactive dihydromorphine in biological fiuids and tissues by means of extraction into organic solvents has been published. ${ }^{1}$ This method gave complete recoveries of known amounts of dihydromorphine added to choroid plexus and renal tissue. In addition, the method was satisfactory for estimation of the radioactive derivatives of morphine and morphinan noted under Materials (see below). The average recoveries of known amounts of these derivatives added to the tissuemedium mixture ranged from 104 to 108 per cent.

The solvent extraction method was always uscd for analysis of radioactive analgesics in renal tissues and in the corresponding incubation media. However, a direct counting procedure (see below) was used for most of the experiments with choroid plexus tissue because (1) there was no evidence for metabolic alteration of the morphine and morphinan derivatives when they were incubated for long periods with choroid plexus (see below), (2) the results were identical when concentrations of the analgesics in the same piece of tissue were estimated with both the specific solvent extraction method and the direct counting procedure, and (3) there was no evidence for a significant degrce of residual binding of the radioactive drugs to the tissue components settling out of the homogenate in the scintillation counting vial.

In the direct-counting procedure, the piece of choroid plexus was weighed on a Cahn M-10 electrobalance and then homogenized in $0.5 \mathrm{ml}$ plain media. Duplicate $0.2-\mathrm{ml}$ aliquots of the homogenate were immediately transferred to scintillation-grade 
glass vials. Single or duplicate $0 \cdot 2-\mathrm{ml}$ aliquots of the corresponding incubation medium were placed in similar vials. Ten milliliters of absolute ethanol:toluene phosphor* $(3: 7, \mathrm{v} / \mathrm{v})$ was added to each vial, and the radioactivity was determined in a liquid scintillation spectrometer (Tri-Carb model 3115). Known quantities of the radioactive drug in the incubation medium (standards) and aliquots of the plain medium (blanks) were analyzed along with each group of unknown samples. Concentrations for the radioactive compounds in tissue ( $\mathrm{n}$-moles/g) and in media (n-moles $/ \mathrm{ml})$ were calculated from the standards. In any given experiment the degree of quenching of phosphorescence as determined by addition of an internal standard or by use of the automatic external standard was constant from sample to sample. Variations in the weight of the tissue sample $(0.500-4.000 \mathrm{mg})$ had a negligible effect on the degree of quenching in the presence of a constant volume of the incubation medium.

Materials. The preparation of tritium-labeled dihydromorphine has been described.7 Levorphan, dextrorphan, and $l$-methorphan were tritiated by New England Nuclear Corp. by the Wilzbach procedure and then purified in our laboratories. ${ }^{8}$ Descriptions of the synthesis of $\mathrm{N}$-methyl- ${ }^{14} \mathrm{C}$-labeled morphine ${ }^{9}$ and levorphan ${ }^{10}$ have been published, as has the method for purification of tritium-labeled nalorphine.11 Hexamethonium-methyl $-14 \mathrm{C}$ dichloride was purchased from New England Nuclear Corp.

Chromatographic identification of narcotic analgesics in tissue. In the experiments with renal slices, the radioactive drugs in tissue and media were always determined by the solvent extraction procedure. The specificity of this procedure for the unchanged drugs was confirmed by paper chromatographic methods published previously. ${ }^{1,12}$

Dihydromorphine-3 $\mathrm{H}$ was incubated for 15 and for 90 min with several pieces of rabbit choroid plexus. A portion of the tissue from each incubation was homogenized in methanol and another portion was homogenized in water. Aliquots of these homogenates and of the incubation media were applied to chromatographic paper, and the chromatograms were developed in each of the three solvent systems described previously. ${ }^{1}$ Each chromatogram contained a single area of radioactivity corresponding in $R_{f}$ to authentic dihydromorphine which was applied to each paper as a control. Theoretically, if as little as 3 per cent of the tissue radioactivity had been present in a form other than dihydromorphine- ${ }^{3} \mathrm{H}$, it would have been detected by these methods.

Similarly, use of paper chromatographic methods produced no evidence of metabolic alteration of the other radioactive morphine and morphinan derivatives after incubation with either kidney slices or choroid plexus. Hexamethonium was not metabolized by rabbit choroid plexus. ${ }^{3}$

\section{RESULTS}

Uptake of narcotic analgesics by renal cortical slices from dogs

The accumulation of dihydromorphine $\left(10^{-5} \mathrm{M}\right)$ by renal cortical tissue slices from dogs proceeded rapidly in an atmosphere of oxygen at $37^{\circ}$ and reached a steady-state distribution between tissue and medium in about $1 \mathrm{hr}$ (Fig. 1). At lower temperatures or in a nitrogen atmosphere, the steady-state tissue concentration was reduced. The simultaneous uptake of inulin, which distributes only to extracellular space, ${ }^{13}$ is shown for comparison.

\footnotetext{
* Toluene phosphor was prepared by dissolving $3 \mathrm{~g} \mathrm{2,5-diphenyloxazole} \mathrm{(PPO)} \mathrm{and} 100 \mathrm{mg}$ dimethyl POPOP (Packard Instrument $\mathrm{Co}$.) in 11 . of reagent-grade toluene.
} 


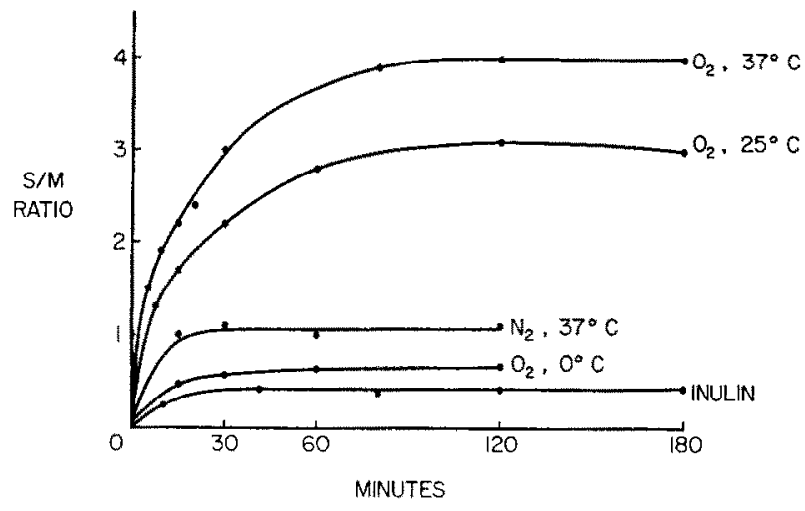

FIG. 1. Accumulation of dihydromorphine with time by renal cortical slices incubated in Ringer's medium with $10^{-5} \mathrm{M}$ dihydromorphine. Incubation temperature and atmosphere ( $\mathrm{O}_{2}$-oxygen$\mathrm{N}_{2}$-nitrogen) are indicated. The $\mathrm{S} / \mathrm{M}$ for dihydromorphine after $15-\mathrm{sec}$ incubation was $0 \cdot 1$, and this value was used as an approximation of zero time. Uptake of inulin $(16 \mathrm{mg} / \mathrm{ml})$ was determined in oxygen at $37^{\circ}$. Each point is a mean of triplicate incubations of tissue slices from a single dog.

Experiments demonstrating inhibition of the tissue accumulation of dihydromorphine by classical metabolic inhibitors were described in an earlier publication. ${ }^{1}$ The addition of 5 or $10 \mathrm{mM}$ acetate to the medium stimulated the uptake of dihydromorphine by slices incubated in oxygen but had no effect on the uptake in nitrogen (Table 1).

TABLE 1. EFFECT OF ADDED SUBSTRATE ON THE UPTAKE OF DIHYDROMORPHINE BY RENAL CORTICAL SLICES

\begin{tabular}{|c|c|c|c|c|}
\hline \multirow{2}{*}{$\begin{array}{l}\text { Dog } \\
\text { No. }\end{array}$} & \multirow{2}{*}{$\begin{array}{l}\text { Incubation } \\
\text { atmosphere }\end{array}$} & \multicolumn{3}{|c|}{ Slice/medium ratio* } \\
\hline & & $\begin{array}{l}\text { DHM } \\
\text { alone }\end{array}$ & $\underset{\text { acetate }}{\mathrm{DHM}}+5 \mathrm{mM}$ & $\underset{\text { acetate }}{\mathrm{DHM}}+10 \mathrm{mM}$ \\
\hline $\begin{array}{l}37 \\
38 \\
39 \\
37 \\
38\end{array}$ & $\begin{array}{l}\text { Oxygen } \\
\text { Oxpgen } \\
\text { Oxygen } \\
\text { Nitrogen } \\
\text { Nitrogen }\end{array}$ & $\begin{array}{l}4 \cdot 2 \\
4 \cdot 3 \\
3 \cdot 5 \\
2 \cdot 2 \\
1 \cdot 3\end{array}$ & $\begin{array}{l}6 \cdot 6(157 \%) \\
5 \cdot 1(119 \%) \\
4 \cdot 5(129 \%) \\
2 \cdot 1 \\
1 \cdot 4\end{array}$ & $\begin{array}{l}5 \cdot 5(131 \%) \\
5 \cdot 1(119 \%) \\
2 \cdot 1 \\
1 \cdot 2\end{array}$ \\
\hline
\end{tabular}

* Each value is a mean for three individual incubations lasting $2 \mathrm{hr}$ at $37^{\circ}$ in medium containing $10^{-5} \mathrm{M}$ dihydromorphine.

When incubated under anaerobic conditions, renal tissue slices accumulated dihydromorphine in proportion to the concentration of the drug in the media. This is shown by an essentially constant slice-medium ratio $(\mathrm{S} / \mathrm{M})$ at different molar concentrations of dihydromorphine (Fig. 2). However, in an oxygen atmosphere the S/M ratio declined with increasing concentrations of dihydromorphine in the medium (Fig. 2). The line connecting the values obtained under oxygen appeared to approach asymptotically the steady-state ratio for anaerobic conditions. Thus the uptake of dihydromorphine under aerobic conditions was in part due to a saturable process. 


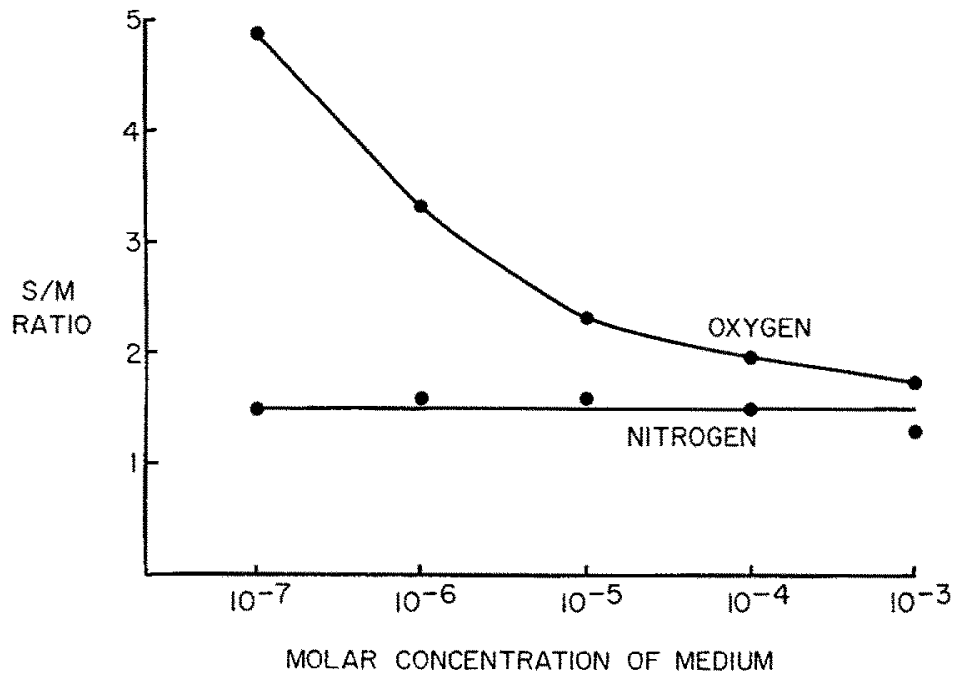

FIG. 2. Steady-state equilibration of dihydromorphine between renal cortical slices and media having different molar concentrations of dihydromorphine. Tissues from one dog were incubated for $2 \mathrm{hr}$ at $25^{\circ}$ in an oxygen or nitrogen atmosphere. Each point represents the mean of triplicate incubations.

In the presence of organic bases, including the narcotic analgesic antagonist nalorphine, the uptake of dihydromorphine was significantly reduced (Table 2). This inhibition could be reversed by increasing concentrations of dihydromorphine in the medium (Fig. 3).

TABLE 2. EFFECT OF ORGANIC BASES ON THE UPTAKE OF DIHYDROMORPHINE BY RENAL CORTICAL SLICES*

\begin{tabular}{lcccc}
\hline \multicolumn{1}{c}{ Organic base } & $\begin{array}{c}\text { Conc. } \\
(\mathrm{M})\end{array}$ & $\mathrm{n}$ & $\begin{array}{c}\text { Per cent of controlt } \\
\pm \text { S.E.M. }\end{array}$ & $P$ Value \\
\hline Mepiperphenidol & $10^{-6}$ & 3 & $69 \pm 4$ & $<0.02$ \\
Nalorphine & $10^{-3}$ & 4 & $67 \pm 3$ & $<0.01$ \\
Nalorphine & $10^{-5}$ & 4 & $74 \pm 5$ & $<0.01$ \\
N-Methylnicotinamide & $10^{-3}$ & 2 & $74 \pm 5$ (range) & \\
\hline
\end{tabular}

* Slices from dog kidneys were incubated for $2 \mathrm{hr}$ at $37^{\circ}$ under oxygen in a medium containing $10^{-5} \mathrm{M}$ dihydromorphine.

$\uparrow$ The number of individual animals is indicated by $n$ in Tables 2-9. Four incubations were performed in the absence and four in the presence of each inhibitor for each animal, and the values are means for two to four animals. A paired comparison was used in calculating $P$ values.

Probenecid also reduced the renal cortex accumulation of dihydromorphine (Table 3). Probenecid has been used as the classic inhibitor of organic acid secretion by the kidney. ${ }^{14}$ In those morphine-like compounds with an ionizable phenolic group (e.g. dihydromorphine, levorphan), transport by the acid secreting mechanism is a possibility. If so, blockade of the phenolic hydroxyl by alkylation (e.g. $l$-methorphan) should preclude transport of the molecule by the acid-secreting mechanism and render the uptake insensitive to inhibition by probenecid, if the latter compound is a specific inhibitor of the acid-secreting mechanism. In fact, $l$-methorphan was avidly accumulated by renal cortical slices (Table 4), and probenecid inhibited the uptake of $l$ methorphan and levorphan to the same degree (Table 3). 


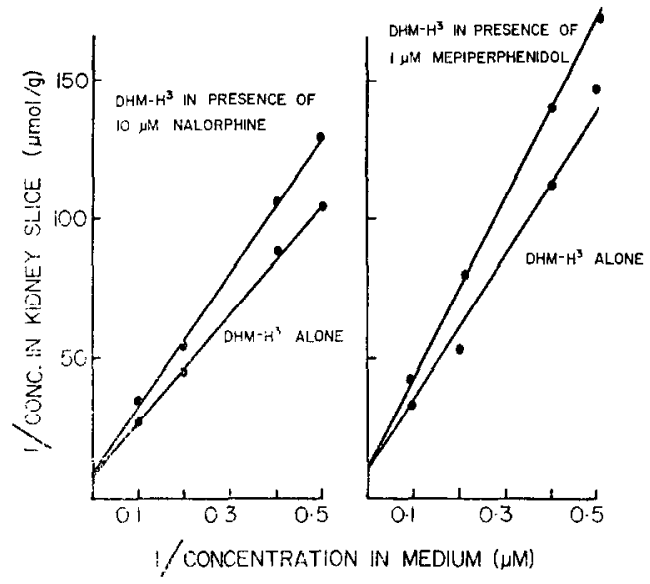

FIG. 3. Uptake of dihydromorphine by renal cortical slices in the presence and absence of nalorphine and mepiperphenidol. Tissues from one dog were incubated for $2 \mathrm{hr}$ at $25^{\circ}$ in an oxygen atmosphere. Each point represents the average of duplicate incubations.

TABLE 3. EFFECT OF PROBENECID ON THE UPTAKE OF NARCOTIC ANALGESICS BY RENAL CORTICAL TISSUE SLICES*

\begin{tabular}{|c|c|c|}
\hline Medium & $\mathbf{n}$ & Per cent of control* \\
\hline $\begin{array}{cc}\text { Dihydromorphine } & 10^{-5} \mathrm{M} \\
\quad+\text { probenecid } & 10^{-5} \mathrm{M} \\
\quad \text { + probenecid } & 10^{-3} \mathrm{M} \\
\text { Levorphan } 10^{-5} \mathrm{M} & \\
\quad \text { + probenecid } & 10^{-3} \mathrm{M} \\
\text { l-Methorphan } & 10^{-5} \mathrm{M} \\
\quad \text { + probenecid } & 10^{-3} \mathrm{M}\end{array}$ & $\begin{array}{l}2 \\
2\end{array}$ & $\begin{array}{cc} & 100 \\
81 \pm 2 \text { (S.E.M.) } \\
41 \pm 5 \text { (S.E.M.) } \\
100 \\
61 \pm 2 \text { (range) } \\
100 \\
59 \pm 2 \text { (range) }\end{array}$ \\
\hline
\end{tabular}

* The conditions of incubation and statistical analysis were the same as described under Table 2.

TABle 4. METABOLIC-DEPENDENT UPTAKE OF NARCOTIC ANALGESICS BY RENAL CORTICAL SLICES

\begin{tabular}{|c|c|c|c|c|}
\hline \multirow{2}{*}{ Narcotic analgesic } & \multirow{2}{*}{ D.R.* } & \multicolumn{2}{|c|}{ Slice/medium ratio } & \multirow{2}{*}{$\begin{array}{l}\text { Net uptake } \\
\left(\mathrm{O}_{2}-\mathrm{N}_{2}\right)\end{array}$} \\
\hline & & Oxygen (n) & Nitrogen (n) & \\
\hline $\begin{array}{l}\text { Dihydromorphine } \\
\text { Morphine } \\
\text { Nalorphine } \\
\text { Levorphan } \\
\text { Dextrorphan } \\
\text { l-Methorphan }\end{array}$ & $\begin{array}{l}1 \cdot 0 \\
1 \cdot 5 \\
1 \cdot 8 \\
3 \cdot 1 \\
3 \cdot 0 \\
7 \cdot 4\end{array}$ & $\begin{array}{r}4 \cdot 1(7) \\
4 \cdot 2(1) \\
4 \cdot 8(2) \\
10 \cdot 8(3) \\
8 \cdot 3(1) \\
20 \cdot 6(2)\end{array}$ & $\begin{array}{l}1 \cdot 7(7) \\
2 \cdot 3(1) \\
3 \cdot 2(2) \\
6 \cdot 4(1) \\
6 \cdot 9(1)\end{array}$ & $\begin{array}{l}2.4 \\
1.9 \\
1.6 \\
4.4 \\
1.4\end{array}$ \\
\hline
\end{tabular}

* Solvent-water distribution ratios were determined for ethylene dichloride and an equal volume of $0.2 \mathrm{M}$ aqueous potassium phosphate at $\mathrm{pH} 7.4$. The values are relative to that of dihydromorphine, which is arbitrarily designated as 1.0 (Mellett, personal communication).

† Multiple incubations were performed for each animal and the mean for one or more animals is shown here. All incubations were for $2 \mathrm{hr}$ at $37^{\circ}$ in media containing $10^{-5} \mathrm{M}$ concentrations of the narcotic analgesics. 
Several derivatives of morphine and morphinan were accumulated in renal slices by a metabolic-dependent process (Table 4). The uptake of these derivatives in a nitrogen atmosphere parelleled their relative lipid solubility, which is indicated by the distribution ratios of these derivatives between ethylene dichloride and $0.2 \mathrm{M}$ aqueous phosphate buffer (Mellett, personal communication). The active component of tissue accumulation (indicated by the difference of the accumulation in oxygen and nitrogen) was not directly related to the lipid solubilities of these derivatives. An element of stereospecificity in the active component is suggested by the differing steady-state ratios for the levo- and dextro-isomers of the morphinan series. Further study is needed to establish the importance of stereospecificity in renal transport of the analgesics.

\section{Uptake of narcotic analgesics by choroid plexus tissue from rabbits}

Accumulation of dihydromorphine $\left(10^{-5} \mathrm{M}\right)$ by rabbit choroid plexus incubated at $37^{\circ}$ was rapid initially and produced a tissue-medium ratio $(\mathrm{T} / \mathrm{M})$ of $6.6 \pm 1.4$ (S.E.M., $\mathrm{n}=4$ ) in $30 \mathrm{~min}$ (Fig. 4). Beyond 30-min of incubation the distribution of the drug between tissue and medium remained nearly constant.

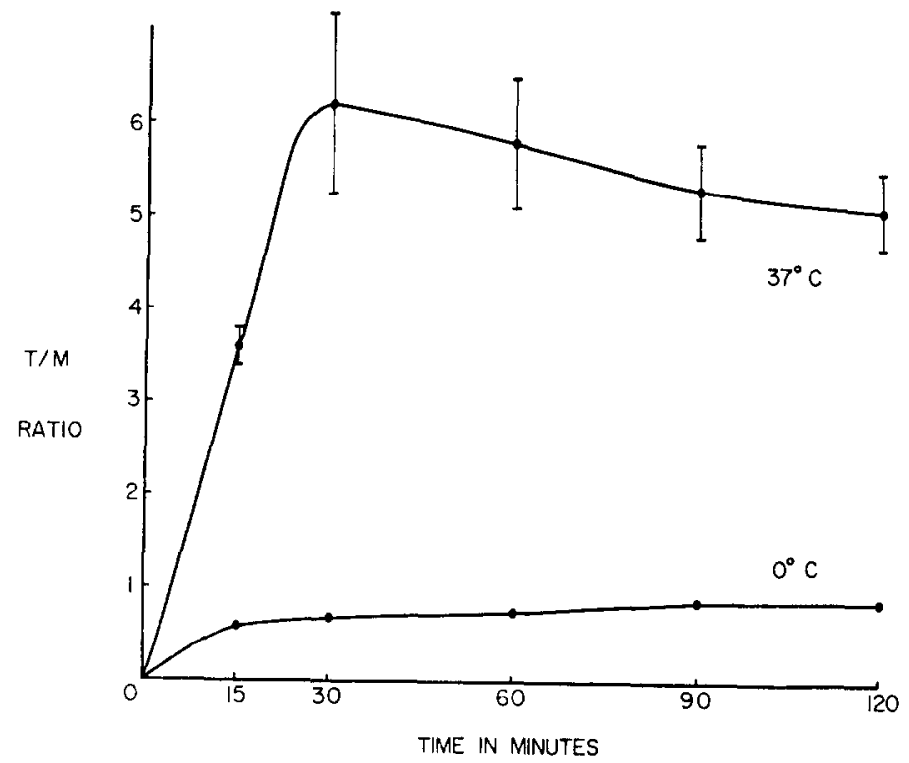

FIG. 4. Accumulation of dihydromorphine with time by choroid plexus incubated in Ringer's medium with $10^{-5} \mathrm{M}$ dihydromorphine and an atmosphere of oxygen. The $\mathrm{T} / \mathrm{M}$ ratio was $0.18 \pm 0.02$ (S.E.M.) after 5 -sec incubation. For tissues incubated at $37^{\circ}$, each point represents the mean \pm S.E.M. for three or four animals. For tissues incubated at $0^{\circ}$, each point is the mean for 2 or 4 animals.

For the remainder of the experiments to be described, uptake of dihydromorphine after 15 or $30 \mathrm{~min}$ of incubation was considered to be representative of the initial rate. Incubation periods of 60 or 90 min were used to measure the steady-state distribution of dihydromorphine between choroid plexus and medium.

At $0^{\circ}$ incubation temperature, the tissue accumulation of dihydromorphine was both slow and limited (Fig. 4). After 90-min incubation the T/M ratio was $0.87 \pm 0.08$ (S.E.M., $n=4$ ), a value approximating that expected for a compound distributing to total tissue water by simple diffusion. 
Several metabolic inhibitors significantly depressed the steady-state accumulation of dihydromorphine at $25^{\circ}$ (Table 5). The same degrees of inhibition seen at $25^{\circ}$ were evident at $37^{\circ}$ for $1 \mathrm{mM}$ iodoacetate and for a nitrogen atmosphere. Combining $1 \mathrm{mM}$ iodoacetate with a nitrogen atmosphere did not result in a greater degree of inhibition.

TABle 5. EFFeCt OF METABOLIC INHIBITORS ON THE ACCUMULATION OF DiHYDROMORPHINE BY CHOROID PLEXUS*

\begin{tabular}{|c|c|c|c|}
\hline Inhibitor & $\mathrm{n}$ & $\begin{array}{l}\mathrm{T} / \mathrm{M} \text { ratio } \\
\pm \mathrm{S} . \mathrm{E} . \mathrm{M} .\end{array}$ & $\begin{array}{l}\text { Per cent of } \\
\text { control }\end{array}$ \\
\hline $\begin{array}{ll}\text { None } & \\
\text { Cyanide } & 10^{-2} \mathrm{M} \\
\text { 2,4-Dinitrophenol } 10^{-3} \mathrm{M} \\
\text { Fluoroacetate } & 10^{-2} \mathrm{M} \\
\text { Iodoacetate } & 10^{-3} \mathrm{M} \\
\text { Nitrogen atmosphere }\end{array}$ & $\begin{array}{r}15 \\
3 \\
3 \\
3 \\
3 \\
15\end{array}$ & $\begin{array}{l}4.2 \pm 0.5 \\
2.4 \pm 0.1 \\
1.8 \pm 0.2 \\
2 \cdot 1=0.2 \\
1.4 \pm 0.2 \\
1.5 \pm 0.2\end{array}$ & $\begin{array}{r}100 \\
72 \\
54 \\
63 \\
42 \\
36\end{array}$ \\
\hline
\end{tabular}

* Tissues were incubated for $90 \mathrm{~min}$ at $25^{\circ}$ under oxygen (except as noted) in medium containing $10^{-5} \mathrm{M}$ dihydromorphine.

Ouabain $\left(10^{-3} \mathrm{M}\right)$ reduced the initial rate of uptake of dihydromorphine to $73 \pm 10$ (S.E.M., $n=4$ ) per cent of control but had no effect on the steady-state accumulation of the analgesic (106 \pm 6 S.E.M., $n-8)$.

Varying the $\mathrm{pH}$ of the medium over the range 6.8-8.0 produced no consistent effect on the uptake under aerobic conditions. Under an atmosphere of nitrogen, increments of $\mathrm{pH}$ resulted in slight increases of dihydromorphine concentration in choroid plexus tissue in equilibrium with the media (Table 6). Unless indicated specifically, all experiments were performed with media adjusted to $\mathrm{pH} 7 \cdot 4$.

TABLE 6. EFFeCTS OF ALTERATIONS IN pH ON THE ACCUMULATION OF DIHYDROMORPHINE BY CHOROID PLEXUS*

\begin{tabular}{|c|c|c|c|c|c|}
\hline \multirow{2}{*}{$\begin{array}{c}\mathrm{pH} \text { of } \\
\text { Medium } \dagger\end{array}$} & \multicolumn{5}{|c|}{$\mathrm{T} / \mathrm{M}$ ratio S.E.M. } \\
\hline & Oxygen & $n$ & Nitrogen & & $\mathrm{n}$ \\
\hline $\begin{array}{l}6.8 \\
7.1 \\
7.4 \\
7.7 \\
8.0\end{array}$ & $\begin{array}{l}4 \cdot 5 \pm 0.3 \\
5 \cdot 2+0.5 \\
5 \cdot 3 \pm 0.5 \\
4 \cdot 1 \pm 0.5 \\
4.3 \pm 1 \cdot 0\end{array}$ & $\begin{array}{r}5 \\
7 \\
12 \\
6 \\
6\end{array}$ & $\begin{array}{l}0.75 \pm 0.1 \\
0 \cdot 89+0.02 \\
1.32 \pm 0.07 \\
1.25 \pm 0.05 \\
1.60 \pm 0.3\end{array}$ & $\begin{array}{l}\text { (range) } \\
\text { (range) } \\
\text { (range) }\end{array}$ & $\begin{array}{l}2 \\
3 \\
3 \\
2 \\
2\end{array}$ \\
\hline
\end{tabular}

\footnotetext{
* Tissues were incubated for $60 \mathrm{~min}$ at $37^{\circ}$ in medium containing $10^{-5} \mathrm{M}$ dihydromorphine.

$\dagger$ The $\mathrm{pH}$ was altered by varying the amount of bicarbonate in the medium while maintaining an atmosphere of $5 \%$ carbon dioxide and $95 \%$ oxygen or nitrogen.
}

The initial rate of uptake of dihydromorphine by choroid plexus in terms of nanomoles per gram of wet weighed tissue demonstrated the characteristics of a saturable process (Fig. 5). That is, the accumulation was not directly proportional to the concentration of dihydromorphine in the medium and tended to approach a maximum. At $10 \mu \mathrm{M}$ the $\mathrm{T} / \mathrm{M}$ ratio averaged $5 \cdot 8$, while at $200 \mu \mathrm{M}$ the average ratio was 3.0. 
Routinely throughout this investigation, $3 \mathrm{ml}$ of medium containing $10 \mu \mathrm{M}(3.05$ $\mu \mathrm{g} / \mathrm{ml}$ ) dihydromorphine was used for incubation of each piece of choroid plexus. This amount of dihydromorphine represented an excess such that the final concentration of the analgesic in the medium never differed from the initial concentration by more than 2 per cent.

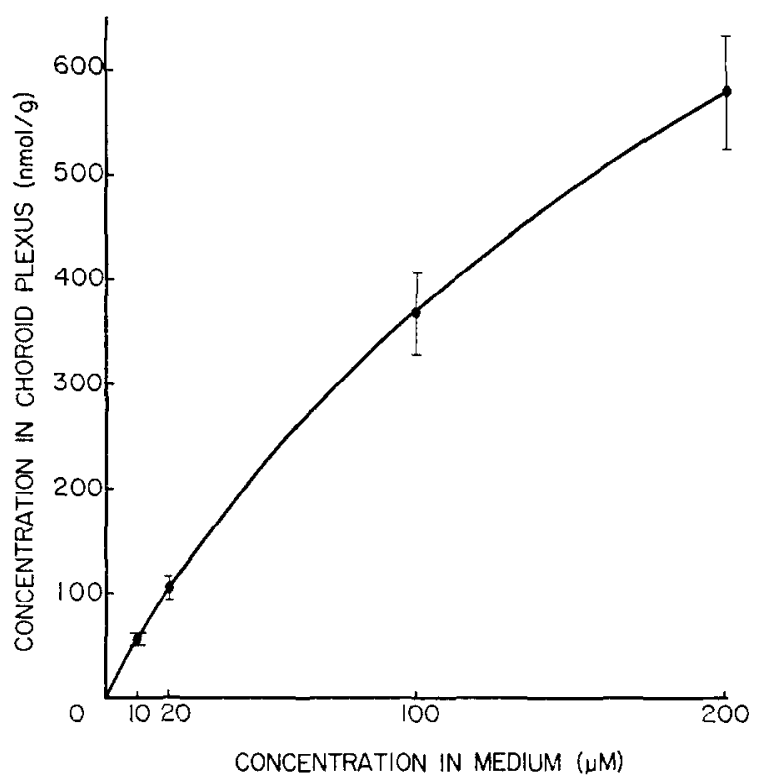

FiG. 5. Relation between concentration of dihydromorphine in medium and in choroid plexus after 15 -min incubation at $37^{\circ}$ in an atmosphere of oxygen. Each point represents the mean \pm S.E.M. for seven animals except for the highest concentration, for which three animals were used.

Organic bases can modify the uptake of dihydromorphine by the choroid plexus. Dependent on the circumstances, there may be depression or there may be stimulation. The following summarizes observations made for the initial rate of uptake and for the steady-state accumulation of dihydromorphine by rabbit choroid plexus in vitro.

Depression of the initial rate of uptake of dihydromorphine was observed with decamethonium, hexamethonium, and mepiperphenidol. In each case the inhibition appeared to be a competitive one (for example, see Fig. 6).*

Depression of the steady-state concentration of dihydromorphine was produced by a variety of organic bases, including the narcotic analgesic antagonist nalorphine (Table 7 and Fig. 7).

Stimulation of the initial rate of uptake of dihydromorphine was marked when the tissue was preincubated with hexamethonium. Pieces of choroid plexus tissue from eighteen animals were preincubated for $1 \mathrm{hr}$ with $10^{-3} \mathrm{M}$ hexamethonium chloride (non-radioactive). They were then transferred to fresh media containing no hexamethonium but containing $10^{-5} \mathrm{M}$ dihydromorphine- ${ }^{3} \mathrm{H}$ and were incubated for $15 \mathrm{~min}$. Other pieces of choroid plexus from the same animals were preincubated in media

\footnotetext{
* The effect of other organic bases on the initial rate has not yet been studied. Lineweaver-Burk plots of the inhibitory effects of decamethonium $\left(10^{-3} \mathrm{M}\right)$ and mepiperphenidol $\left(10^{-3} \mathrm{M}\right)$ were almost identical with that shown for hexamethonium (Fig. 6).
} 
without hexamethonium (control tissue). The uptake of dihydromorphine after preincubation with hexamethonium was $142 \pm 11$ (S.E.M.) per cent compared to the uptake by control tissue $(P<0.01)$.

Stimulation of the steady-state accumulation of dihydromorphine by choroid plexus was observed on several occasions in the presence of organic bases such as

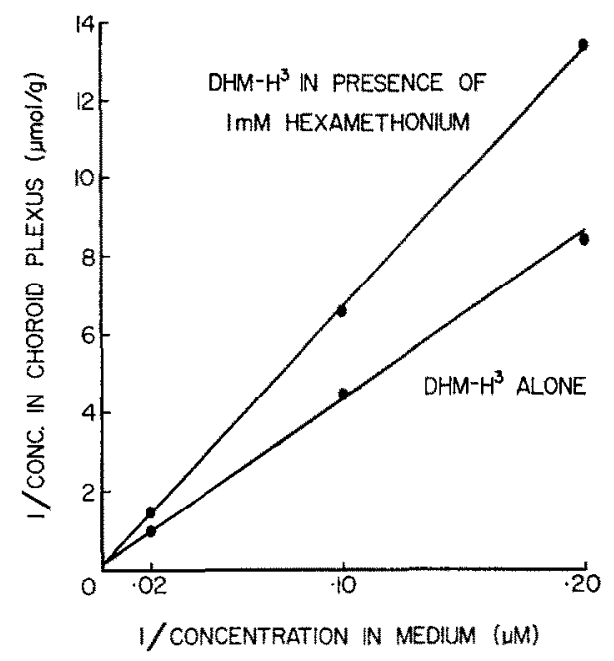

FIG. 6. Uptake of dihydromorphine by choroid plexus in the presence and absence of hexamethonium. Incubation lasted $30 \mathrm{~min}$ at $37^{\circ}$ in an atmosphere of oxygen. The choroid plexus tissue from each animal was divided into a total of six pieces and one piece was incubated at each concentration with or without the inhibitor. Each point represents the mean of four animals (all tissues incubated simultaneously). Lines were fitted to the points by the method of least squares.

TABLE 7. EFFECTS OF ORGANIC BASES ON THE STEADY-STATE ACCUMULATION OF DIHYDROMORPHINE $\left(10^{-5} \mathrm{M}\right)$ RY RABBIT CHOROID PLEXUS*

\begin{tabular}{lcccc}
\hline \multicolumn{1}{c}{ Organic base } & $\begin{array}{c}\text { Conc. } \\
(\mathrm{M})\end{array}$ & $\mathrm{n}$ & $\begin{array}{c}\text { Per cent of control } \\
\pm \text { S.E.M. }\end{array}$ & $P$ Value \\
\hline Choline Cl & $10^{-5}$ & 12 & $125 \pm 15$ & N.S. \\
& $10^{-3}$ & 11 & $73 \pm 6$ & $<0.01$ \\
Decamethonium Br & $10^{-5}$ & 4 & $59 \pm 10$ & $<0.05$ \\
& $10^{-3}$ & 4 & $42 \pm 8$ & $<0.01$ \\
Hexamethonium $\mathrm{Cl}$ & $10^{-5}$ & 10 & $98 \pm 10$ & N.S. \\
& $10^{-3}$ & 8 & $94 \pm 16$ & N.S. \\
Mepiperphenidol Br & $10^{-5}$ & 10 & $80 \pm 8$ & $<0.05$ \\
& $10^{-3}$ & 6 & $31 \pm 5$ & $<0.001$ \\
N-Methylnicotinamide & $10^{-5}$ & 6 & $84 \pm 10$ & N.S. \\
& $10^{-3}$ & 5 & $69 \pm 9$ & $<0.05$ \\
Nalorphine & $10^{-5}$ & 9 & $100 \pm 11$ & $<0.05$ \\
& $10^{-3}$ & 6 & $76 \pm 8$ & $<0$. \\
\hline
\end{tabular}

* Tissues were incubated for $90 \mathrm{~min}$ at $37^{\circ}$ under oxygen in medium containing $10^{-5} \mathrm{M}$ dihydromorphine. A paired comparison with each animal serving as its own control was used to calculate $P$ values. 


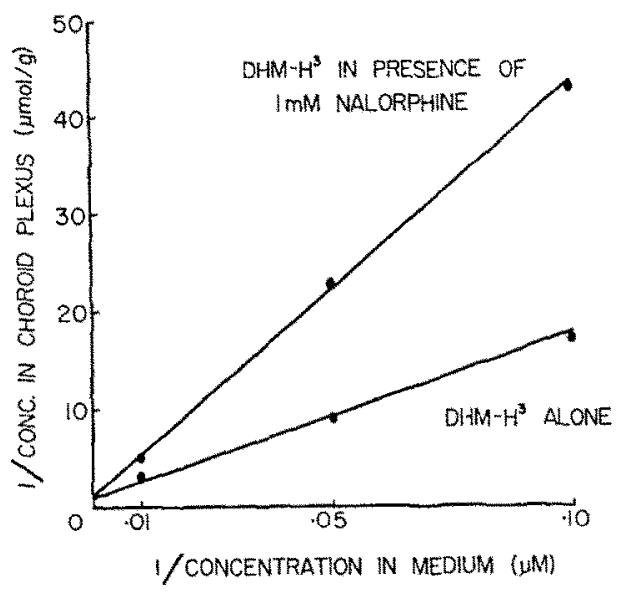

Fro. 7. Uptake of dihydromorphine by choroid plexus in the presence and absence of nalorphine. Conditions of incubation were identical with those described in the legend of Fig. 6 except that the duration was $60 \mathrm{~min}$.

choline, hexamethonium, and nalorphine. This observation at the steady state was not a consistent one, but it was made more frequently with lower concentrations of these inhibitors (e.g. see choline, Table 7) and after prolonged incubation periods.

It is noteworthy that the degree of inhibition of dihydromorphine accumulation by hexamethonium tended to decrease as the incubation periods were prolonged (Table 8 ).

TABLE 8. EFFECT OF HEXAMETHONIUM ON THE UPTAKE OF DIHYDROMORPHINE BY CHOROID PLEXUS INCUBATED FOR VARYING PERIODS OF TIME*

\begin{tabular}{crcc}
$\begin{array}{c}\text { Minutes of } \\
\text { incubation }\end{array}$ & $\mathrm{n}$ & $\begin{array}{c}\text { Per cent of control } \\
\pm \text { S.E.M. }\end{array}$ & $P$ Value \\
\hline 15 & 6 & $78 \pm 6$ & $<0.02$ \\
30 & 10 & $66 \pm 7$ & $<0.01$ \\
60 & 8 & $75 \pm 11$ & $=0.05$ \\
90 & 8 & $94 \pm 16$ & $>0.7$ \\
\hline
\end{tabular}

* Tissues were incubated at $37^{\circ}$ under oxygen in media containing $10^{-5} \mathrm{M}$ dihydromornhine in the presence and absence of $10^{-3} \mathrm{M}$ hexamethonium.

With shorter incubation periods, significant depression of the accumulation was produced by hexamethonium when it was used in a molar concentration 100 times greater than that of dihydromorphine in the medium.*

Additional evidence for the competitive interaction of organic bases and dihydromorphine in choroid plexus was obtained by demonstrating competitive inhibition of the uptake of hexamethonium-methyl ${ }^{14} \mathrm{C}$ chloride by dihydromorphine (Fig. 8). The mutual competitive inhibition of the uptake of hexamethonium and other organic amines has been demonstrated previously for choroid plexus. ${ }^{3}, 4,16$

* Hexamethonium was reported to have no effect on the uptake of morphine by choroid plexus tissue. ${ }^{15}$ However, the authors measured the effect at only one time (1-hr incubation) and with a maximum molar concentration ratio of 4 to 1 , hexamethonium to morphine, in the medium (Takemori, personal communication). 
Probenecid at $10^{-3} \mathrm{M}$ tended to reduce the steady-state concentration of dihydromorphine in choroid plexus to 73 per cent of control $( \pm 13$ S.E.M., $n=3$ ) but had no effect at $10^{-5} \mathrm{M}$. $p$-Aminohippuric acid at $10^{-3} \mathrm{M}$ significantly reduced the steady-state accumulation of dihydromorphine to 79 per cent of control $( \pm 5$ S.E.M., $\mathrm{n}=12$, $P<0.01)$ but had no effect at $10^{-5} \mathrm{M}(107 \pm 6, \mathrm{n}=7)$.

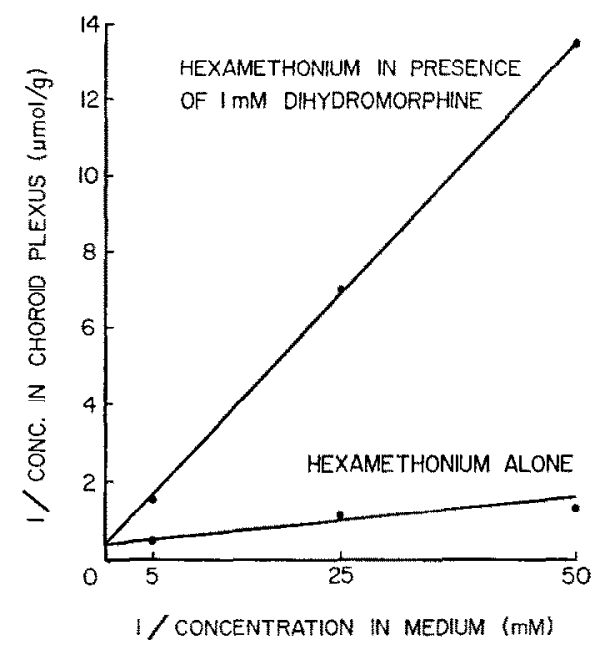

FIG. 8. Uptake of hexamethonium by choroid plexus in the presence and absence of dihydromorphine. Conditions of incubation were identical with those described in the legend of Fig. 6.

A variety of morphine and morphinan derivatives was accumulated by rabbit choroid plexus in vitro (Table 9 ). The list includes morphine and the narcotic analgesic

Table 9. Metabolically dePENDENT uptake of morphine and MORPhinan deRivaTIVES BY RABBIT CHOROID PLEXUS*

\begin{tabular}{|c|c|c|c|}
\hline Compound & $\mathbf{n}$ & $\begin{array}{l}\text { T/M ratio } \\
\pm \text { S.E.M. }\end{array}$ & $\begin{array}{c}\text { Effect of } 10^{-3} \mathrm{M} \text { iodoacetate } \\
(\% \text { of control })\end{array}$ \\
\hline Dihydromorphine- ${ }^{3} \mathrm{H}$ & 6 & $5.7 \pm 0.7$ & 21 \\
\hline Morphine- ${ }^{14} \mathrm{C}$ & 4 & $5 \cdot 1 \pm 0.6$ & 25 \\
\hline Nalorphine ${ }^{3} \mathrm{H}$ & 6 & $5.4+0.5$ & 37 \\
\hline Codeine- $3 \mathrm{H}$ & 2 & $16 \cdot 6 \pm 1 \cdot 3$ (range) & 52 \\
\hline l-Methorphan-3H & 2 & $16.5 \pm 2 \cdot 2$ (range) & 45 \\
\hline Dextrorphan-3H & $\overline{6}$ & $37 \cdot 2 \pm 7 \cdot 8$ & 53 \\
\hline Levorphan- ${ }^{3} \mathrm{H}$ & 6 & $12 \cdot 7 \pm 1 \cdot 8$ & 38 \\
\hline
\end{tabular}

* Each compound was used in a concentration of $2 \times 10^{-5} \mathrm{M}$. Tissues were incubated for 90 min at $37^{\circ}$ in an atmosphere of oxygen.

antagonist nalorphinc, as wcll as the non-analgesic compound dextrorphan. In all cases the $T / M$ ratios were significantly less in the presence of iodoacetate.

The initial rates of uptake of the stereoisomers, levorphan and dextrorphan, were compared at several concentrations, and in each case the rate for dextrorphan was greater than that for levorphan. A reciprocal plot of the data (Fig. 9) indicates that 
levorphan could be accumulated at the same rate as dextrorphan provided its concentration in the medium was sufficiently high. In other words, by analogy to MichaelisMenten formulation, the uptake mechanism has the same $V_{\max }$ for either compound, but the $K_{\mathrm{m}}$ values differ. The accumulation of these stereoisomers at $0^{\circ}$ did not differ markedly; the T/M ratios \pm S.E.M. $(n=6)$ were $4.1 \pm 0.3$ and $4.8 \pm 0.2$ for levorphan and dextrorphan respectively.

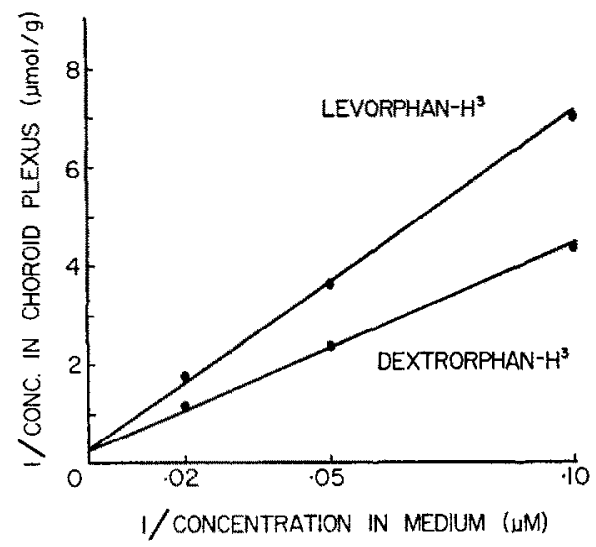

FIG. 9. Relation between concentration of morphinan stereoisomers in medium and in choroid plexus after 15 -min incubation at $37^{\circ}$ in an oxygen atmosphere. The choroid plexus from each animal was divided into a total of six pieces and one piece was incubated with each concentration of levorphan and with each concentration of dextrorphan. Each point represents the mean of four animals (all tissues incubated simultaneously). Lines were fitted to the points by the method of least squares.

\section{Uptake of dihydromorphine by choroid plexus tissue from dogs}

Preliminary experiments demonstrated a metabolically dependent accumulation of dihydromorphine by choroid plexus tissue taken from the lateral ventricles of dogs (Table 10).

TABLE 10. UPTAKE in vitro OF DIHYDROMORPHINE BY CHOROID PLEXUS TISSUE FROM THE LATERAL VENTRICLES OF DOGS*

\begin{tabular}{ccc}
\hline \multirow{2}{*}{ Dog No. } & \multicolumn{2}{c}{ T/M ratio \pm S.E.M. } \\
\cline { 2 - 3 } & Oxygen & Nitrogen + iodoacetate $\left(10^{-3} \mathrm{M}\right)$ \\
\hline 36 & $2 \cdot 8 \pm 0 \cdot 3$ & $1 \cdot 02 \pm 0.07$ \\
37 & $3.3 \pm 0.4$ & $1 \cdot 18 \pm 0.12$ \\
\hline
\end{tabular}

* Tissue from each ether-anesthetized dog was divided into a total of elght pieces. Each piece was incubated for $90 \mathrm{~min}$ at $37^{\circ}$ in medium containing $10^{-5} \mathrm{M}$ dihydromorphine. The values listed are mean values for four incubations.

\section{DISCUSSION}

The characteristics of the uptake of dihydromorphine by renal slices and choroid plexus tissue in vitro were those of an active transport process, namely, transfer against 
an apparent concentration gradient, saturability, substrate competition, stereospecificity, and dependence on aerobic metabolism. The similarity of the uptake processes in the kidney and choroid plexus was striking for the narcotic analgesics. Morphologic and functional similarities between the choroid plexus and the renal tubule have been noted by others. ${ }^{17-19}$

Dihydromorphine (and presumably other morphine and morphinan derivatives) appeared to share the same uptake mechanisms described for other organic bases actively accumulated in renal cortical slices ${ }^{2}$ and in choroid plexus tissue in citro. ${ }^{3,4}$ The same conclusion has been made for the renal tubular secretion of dihydromorphine in the intact animal. ${ }^{1}$ These conclusions are based on mutual competitive inhibition of transport of the narcotic analgesic by organic bases, and vice versa. In addition, the stimulatory effect of organic bases on the accumulation of dihydromorphine by choroid plexus may be another manifestation of the common utilization of the uptake mechanism by the narcotic analgesics and organic bases. Stimulation could occur by way of "counter-transport" or "flow driven by counterflow."20, 21 That is, outflow of hexamethonium may produce increased inflow of dihydromorphine.

In the present study, nalorphine behaved as another organic base rather than a specific inhibitor of narcotic analgesic transport. It was itself actively accumulated by both choroid plexus and renal tissue, and it competitively inhibited the uptake of dihydromorphine by both tissues.

In vivo, nalorphine has been observed to have slight effects on plasma levels and renal tubular secretion of dihydromorphine. ${ }^{1,22}$ Small changes in the concentrations of morphine in the brain and cerebrospinal fluid have been reported for dogs given both morphine and nalorphine. ${ }^{23},{ }^{24}$ On the other hand, morphine appeared to modify the brain concentrations of nalorphine when both were administered to rats. ${ }^{25}$ Whatever the significance of these observations, a mechanism for the reported alterations may involve the interaction of morphine-like drugs and nalorphine with a common transport site.

Potentiating and inhibiting effects of various cholinergic and adrenergic compounds on the central nervous system actions of narcotic analgesics have been reported by numerous authors (see reviews ${ }^{26}, 27$ ). In the present study, choline depressed the uptake of dihydromorphine by the choroid plexus. Choline is transported by the rabbit choroid plexus ${ }^{28}$ and is able to inhibit the uptake of hexamethonium. ${ }^{16}$ Presumably norepinephrine and serotonin would also inhibit transport of dihydromorphine, and vice versa, since they too are transported by the choroid plexus and are competitive inhibitors of hexamethonium accumulation. ${ }^{4}$ Carbachol has been reported to increase the concentration of meperidine (a synthetic narcotic analgesic) in the brain of the intact animal. ${ }^{29}$ Conversely, morphine depressed the uptake of carbachol and of decamethonium by brain slices. ${ }^{30}$ These varied observations seem to point to biological transport sites as loci for interaction of diverse molecules with the narcotic analgesics.

It has been postulated that active transport mechanisms are major factors in bloodbrain and blood-cerebrospinal fluid barrier phenomena. ${ }^{31-33}$ Carrier-mediated transport of organic bases ${ }^{5}$ and of organic acids ${ }^{33}$ out of cerebrospinal fluid has been demonstrated. The choroid plexus has been suggested as one site for transport of such compounds from cerebrospinal fluid to blood. $3,4,33$

Thus, it may be that transport mechanisms are involved in limiting the access of narcotic analgesics to, and in facilitating their elimination from, the central nervous 
system. Relative to other body tissues and fluids, very low levels of morphine and related compounds are found in brain and cerebrospinal fluid after systemic administration of analgesic doses. $11,22,26,34,35$

Acknowledgements-The technical assistance of Miss Janna Strobel, Messrs. Moritz Ziegler and William Beierwaltes, Jr., is gratefully acknowledged. The suggestions of Dr. R. L. Dixon in initiating this study were most helpful. The supplies of non-radioactive dihydromorphine by Dr. N. B. Eddy and of radioactive morphinans by Dr. L. B. Mellett are appreciated.

\section{REFERENCES}

1. C. C. Hug, JR., L. B. Mellett and E. J. Cafruny, J. Pharmac. exp. Ther. 150, 259 (1965).

2. L. Peters, Pharmac. Rev. 12, 1 (1960).

3. Y. TOCHino and L. S. SCHANKER, Am. J. Physiol. 208, 666 (1965).

4. Y. Tochino and L. S. SChanker, Biochem. Pharmac. 14, 1557 (1965).

5. L. S. SChanker, L. D. Prockop, J. SChou and P. Sisodia, Life Sciences 1, 515 (1962); 1, 659 (1962).

6. K. WeLCH, Am. J. Physiol. 202, 757 (1962).

7. C. C. Hug, JR. and L. B. Mellett, Univ. Mich. med. Bull. 29, 165 (1963).

8. L. B. Mellett, Pharmacologist 5, 251 (1963).

9. K. S. ANDERSEN and L. A. WoOds, J. org. Chem. 24, 274 (1959).

10. L. A. Woods, L. B. Mellett and K. S. Andersen, I. Pharmac. exp. Ther. 124, 1 (1958).

11. C. C. Hug, JR. and L. A. Woods, J. Pharmac. exp. Ther. 142, 248 (1963).

12. C. C. Hug, JR, and L. B. MelletT, J. Pharmac, exp. Ther. 149, 446 (1965).

13. L. E. Rosengerg, S. J. Downing and S. Segal, Am. J. Physiol. 202, 800 (1962).

14. I. SPERBER, Pharmac. Rev. 11, 109 (1959).

15. M. W. Stenwick and A. E. TAKemori, Fedn Proc. 25, 415 (1966).

16. Y. Tochino and L. S. SChANKER, Am. J. Physiol. 210, 1229 (1966).

17. D. P. Rall and C. G. Zurrod, Ann. Rev. Pharmac. 2, 109 (1962).

18. H. Davson, Ergebn. Physiol. 52, 20 (1963).

19. D. P. RaLl, in The Cellular Functions of Membrane Transport (Ed. J. F. HoffMAN), Prentice-Hall, New Jersey (1964).

20. H. N. Christensen, Biological Transport. Benjamin, New York (1962).

21. W. Wilbrandt and T. Rosenberg, Pharmac. Rev. 13, 109 (1961).

22. C. C. HuG, $\mathrm{J}_{\mathrm{R}}$, Tritium-Labeled Dihydromorphine. Doctoral dissertation, University of Michigan (1963).

23. S. J. Mulé, L. A. Woods and L. B. MeLletT, J. Pharmac. exp. Ther. 136, 242 (1962).

24. S. J. Mulé, J. Pharmac. exp. Ther. 148, 393 (1965).

25. T. Johannesson and K. Milthers, Acta pharmac, tox. 20, 80 (1963).

26. F. F. Foldes, M. Swerdlow and E. S. Srker, Narcotics and Narcotic Antagonists. Thomas, Springfield, III. (1964).

27. A. K. Reynolds and L. O. Randall, Morphine and Allied Drugs. Univ. of Toronto Press, Toronto (1957).

28. Y. Tochino and L. S. SCHANKer, Pharmacologist 6, 177 (1964).

29. J. Pórszàsz, J. Venulet and K. Gibiszer-Porszasz, Acta physiol. hung. 5, 509 (1954).

30. D. B. TAYLOR, R. Creese and R. CASE, Life Sciences 4, 845 (1965).

31. O. Steinwall, Acta psychiat. scand. suppl. 150, 314 (1961).

32. E. Hansson and O. Steinwall, Acta physiol. scand. 54, 339 (1962).

33. J. R. Pappenheimer, S. R. Heisey and E. F. Jordan, Am. J. Physiol. 200, 1 (1961).

34. S. J. MuLé and L. A. Woods, J. Pharmac, exp. Ther. 136, 232 (1962).

35. L.B. Mellert, Bull. Drug Addiction and Narcotics, Appendix 12, 3822 (1964). 